\title{
Reattachment of fractured anterior tooth fragment: An approach in endo esthetic view
}

\author{
Rafeza Sultana, Md. Mujibur Rahman Howlader, Md. Shamsul Alam, Md. Ali Asgor Moral and Khaleda Akter
}

\begin{abstract}
Article Info
Department of Conservative Dentistry and Endodontics, Bangabandhu Sheikh Mujib Medical University, Shahbag,

Dhaka, Bangladesh

BSMMU J 2016; 9: 113-116

For Correspondence:

Rafeza Sultana

rafezasultana@gmail.com

Received:

Accepted:

Available Online:

2 February 2016

23 March 2016

19 August 2016

ISSN: 2074-2908

DOI: $10.3329 /$ bsmmuj.v9i2.29045

D.1. $10.3329 / 5$

Available at:

www.banglajol.info

A Journal of Bangabandhu Sheikh Mujib Medical University, Dhaka, Bangladesh
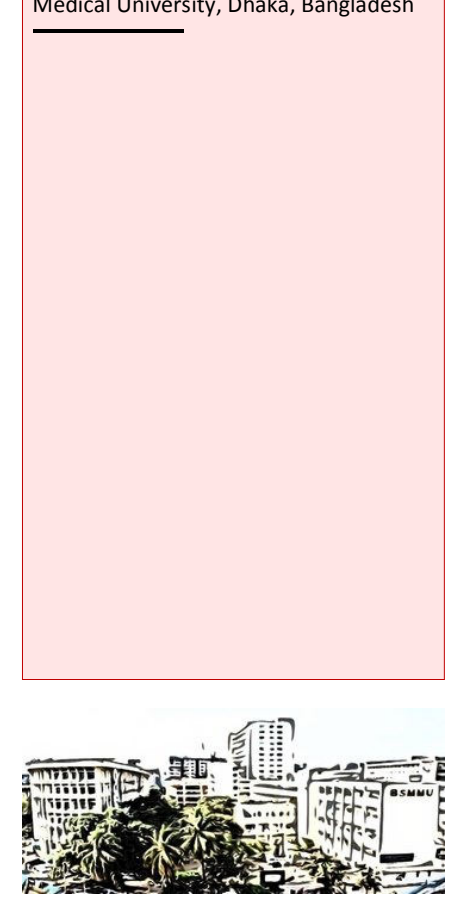

\section{Introduction}

Almost every dental expert is familiar with the patient having traumatized tooth at their regular practice. The most affected teeth are maxillary incisors due to their anterior position and protrusion. The common etiological factor of crown or crown root fracture in the permanent dentition is injury caused by fall, contact sports, automobile accident and foreign body striking the teeth. Esthetic rehabilitation of crown fractures of the maxillary anterior teeth is one of the greatest challenges to the dental specialist. The patients are very conscious about their appearance where as the specialist has to consider long term biological function of that tooth in addition to esthetic. Traditionally such injuries have been restored with composite resin, 1 but they have some disadvantages of color match and variable wear.2 On the other hand, reattachment of fractured fragment may offer the following advantages: a) better esthetic and achievement of lifelike translucency, b) require less time, c) a positive emotional and social response from the patient's side and d) relatively inexpensive procedure. 3

If a broken tooth fragment is available and in a good condition the restoration of the tooth using its own fragment has been suggested. $\underline{4}$
\end{abstract}

\section{Case Report}

A newly married 27 year-old-male patient reported to the Department with the chief complaint of broken upper front tooth following trauma due to hard substance striking while taking food 7 days back.

His medical history was nothing contributory. Clinical examination revealed a complicated crown fracture which extended horizontally from mesial to distal and angulated incisally from palatal to labial with pulp exposure on the labial surface of right maxillary central incisor. Fracture was not evident labially. There was no apparent trauma to the adjacent teeth and soft tissues. Radiographic examination revealed an oblique fracture palato-labially. After routine history taking, examination and based upon patient's desire, a treatment plan was formulated that included endodontic treatment and reattachment of fractured portion of tooth with light activated flowable composite resin using a fiber reinforced post.

In the first appointment a single visit endodontic treatment was performed. Under local anesthesia, the pulp was extirpated and the working length was determined by working length measuring $\mathrm{X}$-ray. Then the root canal was prepared as standardized technique at 17 
mm working length up to $70 \mathrm{~K}$ file and obturated with Gutta Percha by lateral condensation technique.

The fractured fragment was completely separated, dehydrated and chalky white in appearance. In order to prevent dehydration and to get the natural appearance, the fractured fragment was preserved in normal saline for 7 days. After 7 days, in the next visit the GP was partially removed by pesso-reamer (No. 1) leaving $5 \mathrm{~mm} \mathrm{GP}$ at the apex to maintain a tight apical seal. A post hole was prepared within the canal and a perfect diameter (large) sized glass fiber composite post (Glassix, Nordin) was cemented with the root canal using glass ionomer luting cement (GC corporation). An internal groove was made both in fractured fragment and the palatal aspect of the tooth where the fiber post and composite would occupy. Acid etching was done on both the fragment and the tooth using $37 \%$ orthophosphoric acid for $15 \mathrm{sec}$ and thoroughly rinse off. A bonding agent (beautibond, shofu) was applied on both substrates and cured according to manufacturer instructions.

Then the fragment was reattached with flowable composite resin (beautifil flow, shofu). The excess resin was removed with an excavator and light cured for $30 \mathrm{sec}$ from buccal and palatal aspect. Final finishing and polishing were done. Occlusion was cheeked and post-operative instructions were given. Patient was recalled after 7 days for evaluation. Clinical and radiological examination were carried out after 1, 3, 6 and 12 months to confirm the satisfactory esthetic and functional outcome of the treatment with no associated endodontic or periodontal problem.

\section{Discussion}

Up to date, a lot of deferent approaches are proposed for treatment of fractured tooth depending on location of the fracture such as a) reattachment of the fractured fragment, b) composite restoration, c) orthodontic extrusion, d) surgical extrusion and e) crown lengthening. .5

In recent years, due to remarkable advancements of adhesive systems and resin composites, it is now possible to achieve excellent results with reattachment of tooth fragments provided that the biological factors, materials, and techniques are logically assessed and managed.6 As with the conventional restoration, restorative success depends on proper case selection, strict adherence to sound principles of periodontal and endodontic therapies, and the techniques and materials for modern adhesive dentistry..$\underline{7-9}$

In the present case of complicated crown fracture requiring endodontic therapy, the fractured fragment is available and reattachment of the fragment with fiber post is performed to retain the fractured segment and reduce the stress on the luting material. The posts interlock the two separate fragments

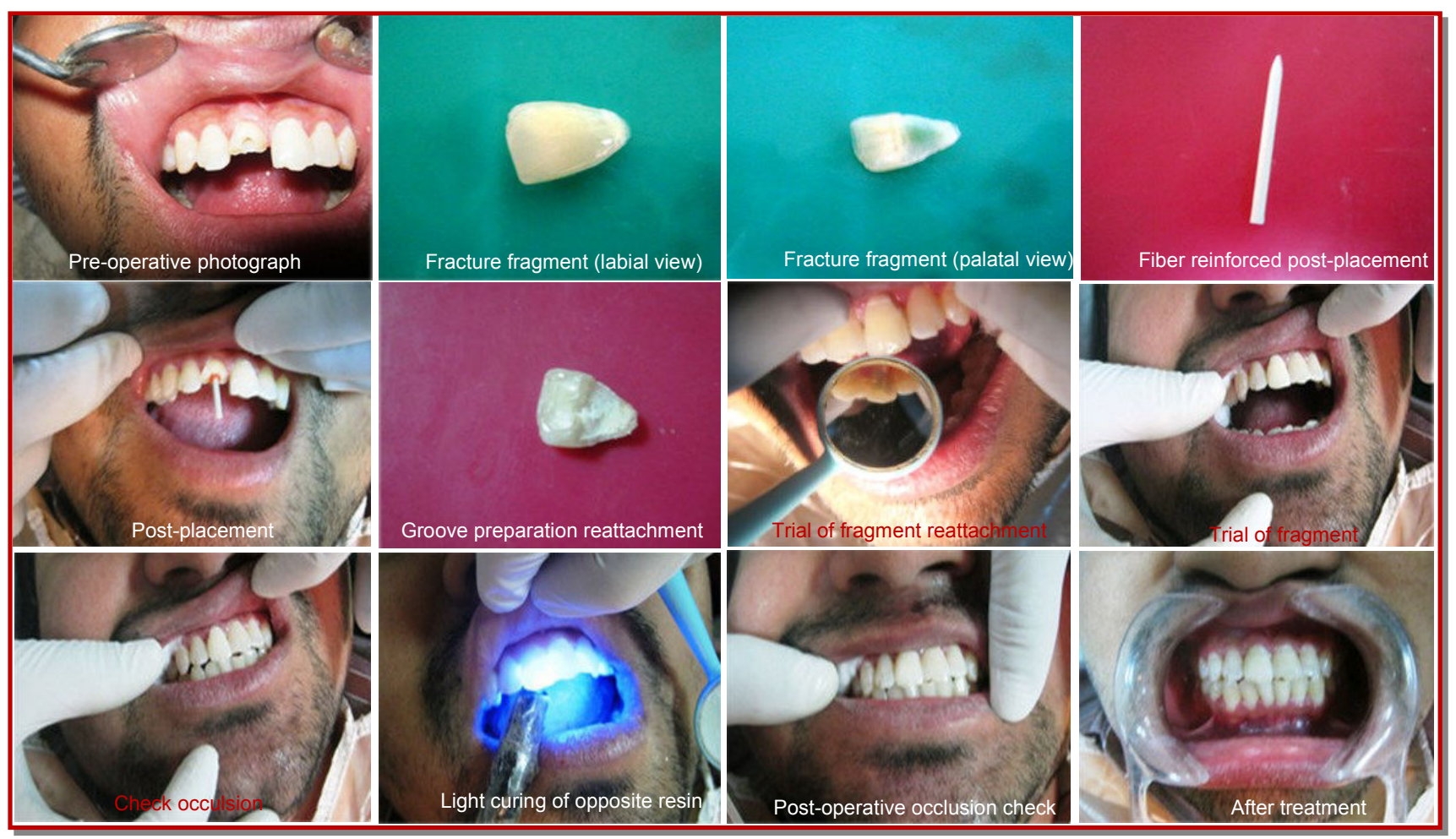

Figure 1: Various steps of reattachment technique 


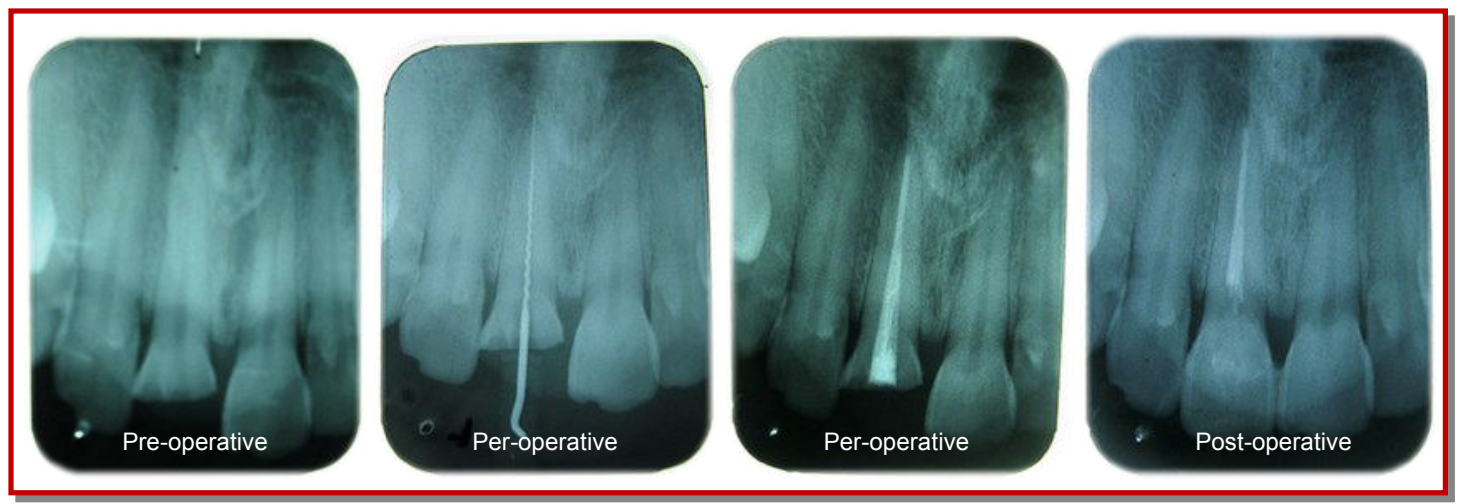

Figure 2: Radiographic assessment

and minimize the stress on the remaining tooth structure. The use of the natural tooth substance offers a conservative, esthetic, and economical option that provides good and long lasting esthetics, restores function, results in a positive psychological response, and is certainly a simple procedure. Adhesive post is used as it has the potential for increased retention, is more flexible, and has modulus of elasticity approximately same as dentin, and when bonded with resin cement it distributes forces evenly along the root. $\underline{10}$

The most common complication is debonding of post and core system.11 Another reason for failure is root fracture. $\underline{12}$ Restoration with cast metal posts can cause wedging forces coronally that may result in irreversible failure because of fracture of an already weakened root. $\underline{13}$ Whereas fiber-reinforced composite resin post has demonstrated negligible root fracture. Studies have indicated that dentinbonded resin post-core restorations provide significantly resistance to fracture than cemented custom cast posts and cores. $\underline{14}$ In addition; the fiberreinforced posts are used with minimal preparation because it uses the undercuts and surface irregularrities to increase the surface area for bonding, thus reducing the possibility of tooth fracture during function or traumatic injury. $\underline{15}$

Various studies reported that sectional obturation of root canal (at the apex) and use of dual cure resin play an important role in the successful treatment outcome of reattachment technique. Use of a fiber post luted with dual cure resin increase the retention of the segment and provides a monoblock effect by locking the core material (fiber post) with the dentinal wall of root canal without leaving any gaps. Most concerns about reattachment technique have been directed towards the fractured strength of the restored tooth. There are several reinforcement techniques adapted to strengthen the tooth structures like a) circumferential bevel, b) external chamfer, c) ' $\mathrm{V}$ ' shaped bevel, d) placement of internal grooves and e) superficial over contour of restorative material over the fracture line and pulp chamber, in case of complicated fracture. $\underline{16}$
The clinician must consider that a dry and clean working field and proper use of bonding protocols and bonding materials is the key to achieve success in adhesive dentistry.

\section{Conclusion}

The reattachment of the tooth fragment is possible only when the fragment is available and can be improved with different adhesive techniques and restorative materials. The main concern is to elucate the population to preserve the fractured fragment and seek immediate dental care.

\section{Ethical Issue}

Written and signed informed consent from the guardian was taken for publishing this case report.

\section{References}

1. Attila IO, Cenk MHA, Serdar MT. Multidisciplinary approach to the rehabilitation of a crownroot fracture for immediate esthetics. Dent Traumatol. 2006; 22: 48-52.

2. Badami A, Dunnes, Scheer B. As in vitro investigation into shear bond strengths of two dentine bonding agents used in the reattachment of incise edge fragments. Endo Dent Traumat. 1995; 11: 129-35.

3. Baratieri LN, Monteiro S. tooth fracture reattachment: Case reports. Quint Int. 1990; 21: 261-70.

4. Yilmaz Y, Zehir C, Eyuboglu O, Belduz N. evaluation of success in the reattachment of control fractures. Dent Traumatol. 2008; 24:151-58.

5. Georgia. V. Macedo GV, Patrica Diaz, Carlos Augusto. Reattachment of anterior tooth fragment: A conservative approach. J Esthet Restor Dent. 2008; 20: 5-20.

6. Vashisth P, Mittal M, Singh AP. Immediate re- 
attachment of fractured tooth segment: A biological approach. Indian J Dent Res Rev. 2012; 7: 72-74.

7. Salameh Z, Sorrentino R, Papacchini F, Ounsi HF, Tashkandi E, Goracci C, Ferrari M. Fracture resistance and failure patterns of endodontically treated mandibular molars restored using resin composite with or without translucent glass fiberpost. J Endod. 2006; 32: 7752-55.

8. Cavalleri G, Zerman N. Traumatic crown fractures in permanent incisors with immature roots: A follow-up study. Endo Dent Traumatol. 1995; 11: 294-96.

9. Lowey MN. Reattachment of a fractured central incisor tooth fragment. Brit Dent J. 1991; 170: 8.

10. Lokesh P, Kala M. Management of mild-root fracture using MTA and fiber post to reinforce crown: A case report. Indian J Dent Res Rev. 2008; 3: 3236.

11. Torbjörner A, Karlsson SO, Ödman PA. Survival rate and failure characteristics for two post designs. J Prosthetic Dent. 1995; 73: 439-44.

12. Asmussen E, Peutzfeldt A, Heitmann T. Stiffness, elastic limit, and strength of newer types of endodontic posts. J Dent. 1999; 27: 275-78.

13. Deutsch AS, Cavallari J, Musikant BL, Silverstein L, Lepley L, Petroni G. Root fracture and the design of prefabricated posts. J Prosthet Dent. 1985; 53: 637-40.

14. Akkayan B, Gülmez T. Resistance to fracture of endodontically treated teeth restored with different post systems. J Prosthet Dent. 2002; 87: 431-37.

15. Beg RT, Parker MW, Judkins JT, Pelleu GB. Effect of dentinal bonded resin post-core preparations on resistance to vertical root fracture. J Prosthet Dent. 1992; 67: 768-72.

16. Trabert KC, Caputo AA, Abou-Rass M. Tooth fracture: A comparison of endodontic and restorative treatments. J Endo. 1978; 4: 341-45. 